\title{
Chronologie concernant les têtes tatouées et momifiées māori ou toi moko (aussi connues sous le terme de moko mokai)
}

Philippe Peltier et Magali Mélandri

\section{(2) OpenEdition \\ Journals}

Édition électronique

URL : http://journals.openedition.org/jso/6638

DOI : $10.4000 /$ jso. 6638

ISSN : $1760-7256$

Éditeur

Société des océanistes

Édition imprimée

Date de publication : 30 juin 2012

Pagination : 28-30

ISBN : 978-2-85430-032-1

ISSN : 0300-953x

Référence électronique

Philippe Peltier et Magali Mélandri, «Chronologie concernant les têtes tatouées et momifiées māori ou toi moko (aussi connues sous le terme de moko mokal) », Journal de la Société des Océanistes [En ligne], 134 | 1er semestre 2012, mis en ligne le 12 juillet 2012, consulté le 02 mai 2019. URL : http:// journals.openedition.org/jso/6638; DOI : 10.4000/jso.6638 


\title{
Chronologie concernant les têtes tatouées et momifiées māori ou toi moko (aussi connues sous le terme de moko mokai)
}

\author{
établie par \\ Philippe PELTIER et Magali MÉLANDRI
}

1768-1771 : Premières têtes momifiées collectées lors du voyage de James Cook. Joseph Banks, à Queen Charlotte Sound, échange une tête le 20 Janvier 1770 contre une " pair of white linen drawers ». Quelques jours plus tard un Māori revient sur l'Endeavour et propose quatre têtes supplémentaires.

1800-1831 : Les nombreux conflits entre iwi (tribus) māori entraînent des échanges extensifs de têtes contre des armes. Le pic de ces échanges se situerait entre 1820 et 1831 . Ils se concentraient dans les régions de la Bay of Islands, Kapiti Island, Foveaux Strait, Otago et Murihiku.

1831 : Le gouverneur Darling, à Sydney, interdit le trafic des têtes māori sur les bateaux ( $S y d$ ney Act) (La Nouvelle-Zélande est à cette époque administrée par l'État du New South Wales). Une amende de $£ 40$ peut être appliquée aux capitaines contrevenants. Le commerce des têtes continue cependant en Nouvelle-Zélande.

Petit à petit la pratique du tatouage disparaît dans la société māori. Elle connaîtra une courte renaissance dans les années 1860 lors des Māori Wars et les dernières têtes produites le sont probablement dans ces années.

1896: Le Major-General Horatio Gordon Robley publie Moko or Maori Tattoing à Londres chez Chapman et Hall. Ce livre qui sert toujours de référence, contient de nombreux dessins de moko mokai effectués lors du séjour de l'auteur en Nouvelle-Zélande entre 1863 et 1866. À son retour en Angleterre, il commence à collectionner des têtes momifiées. Sa collection en comportera 35 qu'il propose à la vente en 1908 au gouvernement de la Nouvelle-Zélande. Après le refus d'achat de ce dernier, sa collection sera vendue à l'American Museum of Natural History de New York pour $£ 1,250$.

Dans les années 1970, des jeunes māori des milieux urbains, à la recherche de signes identitaires forts et de l'affirmation de leur tino rangatiratanga (auto-détermination ou souveraineté), redécouvrent l'art du tatouage.

1984 : L'exposition Te Māori qui a lieu au Metropolitan Museum de New York marque le début d'une prise de conscience par les communautés māori. Le retour des objets exposés à New York est prétexte à des expositions dans les différents musées en Nouvelle-Zélande. Celles-ci favorisent l'émergence de l'intérêt pour les taonga (les trésors) dont les moko mokai font partie.

1987 : L'University College de Londres et le Museum of Ethnology de Stockholm restituent leurs têtes māori au Musée national de Nouvelle-Zélande Te Papa Tongarewa.

1990 : Le Museum of Victoria de Melbourne et le National Museum of Ireland de Dublin rendent leurs têtes māori au Musée national de Nouvelle-Zélande Te Papa Tongarewa.

1991 : l'Ulster Musem de Belfast rapatrie ses têtes māori au Musée national de NouvelleZélande Te Papa Tongarewa.

1992: Le Cultural Conservation Advisory Council (CCAC) est constitué. Il lance le programme de rapatriement des restes humains māori en Nouvelle-Zélande. Le CCAC est rattaché au National Museum / Te Papa Tongarewa de Nouvelle-Zélande.

En Juin, suite à la visite de son directeur, Alan Baker, le Museum für Völkerkunde de Bâle met 
en dépôt au Te Papa la tête tatouée qui appartient à la Société des Amis du musée. Le musée d'ethnographie de Genève restitue ses têtes māori au Musée national de Nouvelle-Zélande Te Papa Tongarewa.

1994 : Le Manchester Museum et la NewZealand High Commission de Londres rendent leurs têtes māori au Musée national de Nouvelle-Zélande Te Papa Tongarewa.

1996 : Le Royal Albert Memorial Art Gallery and Museum d'Exeter et le Lichfield Museum du Staffordshire restituent leurs têtes māori au Musée national de Nouvelle-Zélande Te Papa Tongarewa.

1998 : Le National Museum du Danemark, le Queensland Museum de Brisbane, le Whity Museum de Leeds, le Scarborough Museum du North Yorkshire rapatrient leurs têtes māori au Musée national de Nouvelle-Zélande Te Papa Tongarewa.

1999 : L’Université d'Edinburgh et le National Museum de cette ville rendent leurs têtes māori au Musée national de Nouvelle-Zélande Te Papa Tongarewa.

2000 : Le South Australian Museum d'Adelaide restitue ses têtes māori au Musée national de Nouvelle-Zélande Te Papa Tongarewa.

Février 2001: Devant le nombre de restitutions, un protocole pour le retour des koiwi tangata (les squelettes humains māori ${ }^{1}$ ) est élaboré par le Te Papa Tongarewa; l'Australian Museum de Sydney rapatrie ses têtes māori au Musée national de Nouvelle-Zélande Te Papa Tongarewa.

Mai 2004: Le Museo Etnografico Juan Ambrosetti de Buenos Aires rend une tête tatouée rentrée dans ses collections en 1910 puis en août 2004, le Bishop Museum d'Hawaï, sous l'autorité du Hawai'i and Native Burial Program, restitue quatre têtes māori.

2003 : Le gouvernement de Nouvelle-Zélande soutient officiellement la politique de rapatriement des tūpunalkarapuna (respectivement ancêtres māori et ancêtres moriori - les habitants des Chatham Islands) et donne mandat au Te Papa pour organiser ces rapatriements. Le Karanga Aotearoa Repatriation Programme (programme de rapatriement) est établi (voir http://www.tepapa.govt.nz/aboutus/repatriation/ Pages/overview.aspx). Cet organisme discute directement avec les $i w i$ (tribus) pour organiser et déterminer le futur des restes humains rapatriés.
2005 : Le Victoria Museum, l'Université de Melbourne, le State Coroner Office de Melbourne, le Rijkmuseum voor Volkenkunde de Leyde, la Kelvingrove Art Gallery de Glasgow, le Suffolk Regiment Museum, la Perth Art Gallery and Museum d'Écosse, le Saffron Walden Museum de l'Essex, le Leeds Museum d'Exeter, le Cambridge University Museum of Archaeology and Anthropology, le Royal Albert Memorial Art Gallery and Museum d'Exeter restituent leurs têtes māori au Musée national de Nouvelle-Zélande Te Papa.

2006 : L'Überseemuseum de Brême rend ses têtes au Musée national de Nouvelle-Zélande Te Papa Tongarewa.

2007 : Le Marischal Museum d'Aberdeen, le Tasmamian Museum and Art Gallery, le National Museum of Australia de Canberra, l'Australian National Wildlife collection et l'Institut d'Anatomie de Canberra, le National Museum de Liverpool, le Field Museum de Chicago, le Bristol Museum, le Royal College of Surgeons, London and Hunterian collection, le BARTS and the London Queen Mary School of Medecine and Dentistry, le Bexhill Museum du Sussex, le Hancock Museum de Newcastel, le National Museum of Liverpool, le Swansea Museum, le Plymouth Museum, l'University College du Sussex rendent leurs têtes au Musée national de Nouvelle-Zélande Te Papa Tongarewa.

Octobre 2007 : Le conseil municipal de Rouen approuve à l'unanimité la restitution de la tête māori, objet d'un don en 1875 au Muséum municipal d'histoire naturelle.

27 décembre 2007 : un arrêt du tribunal administratif de Rouen, saisi par le ministère de la Culture, annule la décision du conseil municipal car suivant les termes de la loi relative aux musées de France de janvier 2002, « les biens constituant les collections des musées de France appartenant à une personne publique font partie de leur domaine public et sont, à ce titre, inaliénables ». Ils nécessitent, pour lever cette inaliénabilité, une loi.

2008 : Au Canada, le Royal Ontario Museum de Toronto, l'University of British Columbia Museum of Anthropology de Vancouver, le Musée des Civilisations d'Ottawa et, au Royaume-Uni, l'Oxford Museum of Natural History, le Manchester Museum, le Cuming Museum de Londres, le National Museum of Scotland Department of Zoology and Geology rendent leurs têtes tatouées au Musée national de Nouvelle-Zélande Te Papa Tongarewa.

1. Selon Natacha Gagné (com. pers.), cela veut dire littéralement « os, ossements humains », mais c'est plus largement interprété aujourd'hui comme signifiant « restes humains » ou « restes ancestraux ». 
8 février 2008: Madame Catherine MorinDessailly, alors conseillère municipale à Rouen et sénatrice, dépose une proposition de loi « visant à autoriser la restitution par la France des têtes māories ».

Avril 2008: Le conseil des Trustees du British Museum de Londres accepte le principe de rapatriement de neuf fragments d'os humains (à l'exclusion des têtes tatouées) au Musée national de Nouvelle-Zélande Te Papa Tongarewa (sur la justification de cette décision voir http:// www.britishmuseum.org/the_museum/news_and _press/human_remains/repatriation_to_new_ zealand.aspx).

2009 : Le Maclay Museum de l'Université de Sydney, le National Museum Wales de Cardiff, le Hunterian Museum and Art Gallery de l'Université de Glasgow, le Museum of World Culture de Göteborg, le Gothenburg Museum of Natural History, le Trinity College de Dublin rendent leurs têtes tatouées au Musée national de Nouvelle-Zélande Te Papa.

22 et 23 février 2009 : Le musée du quai Branly organise un colloque sur les restes humains. Madame la sénatrice Morin-Dessailly y prononce une communication. Les actes de ce colloque sont consultables en ligne (http://www. quaibranly.fr/fr/programmation/manifestationsscientifiques/manifestations-passees/colloqueset-symposium/symposium-international-descollections-anatomiques-aux-objets-de-culteconservation-et-exposition-des-restes-humainsdans-les-musees.html).

29 juin 2009 : La loi est votée à l'unanimité par le Sénat. Fréderic Mitterrand prononce à cette occasion son premier discours en tant que ministre de la Culture. Le rapport de Philippe Richert est consultable en ligne (http://www.senat. fr/rap/108-482/108-482.html).

29 avril-4 mai 2010 : L'Assemblée nationale vote la loi n ${ }^{\circ} 2010-501$ portant sur la « Restitu- tion par la France des têtes māori à la NouvelleZélande et relative à la gestion de collections ». Le texte comporte deux articles. Promulgué le 18 mai 2010, il est publié au Journal officiel le 19 mai 2010 (voir http://www.assemblee-nationale. fr/13/dossiers/restitution_tetes_maories.asp).

Les résultats des examens menés sur les têtes tatouées du musée du quai Branly montrent que, sur les sept têtes conservées, cinq présentent des tatouages post-mortem et qu'un sujet serait vraisemblablement féminin. La majorité d'entre elles correspondent à des individus jeunes. Un crâne présente la trace d'un traumatisme important ayant entrainé la mort. Ils démontrent aussi des habitudes alimentaires très différentes suivant les individus.

2011: La Lund University, le Museum of World Culture et le Senckerburg Museum de Francfort, le département d'Anatomie et le Museum of Culture History d'Oslo, le musée d'histoire naturelle de Rouen rendent leurs têtes tatouées au Musée national de Nouvelle-Zélande Te Papa Tongarewa.

2012: Le Muséum national d'histoire naturelle de Paris, le Musée national de la Marine, le musée du quai Branly, les Muséums de Nantes et de Lille, le Musée des Beaux-Arts de Dunkerque, le Musée des Confluences de Lyon, le musée de Sens, le Musée d'Arts africains, océaniens, amérindiens de Marseille, le Muséum de l'Université de Montpellier rendent leurs têtes tatouées au Musée national de Nouvelle-Zélande Te Papa Tongarewa. La cérémonie a lieu au musée $\mathrm{du}$ quai Branly en présence des différents directeurs de musées, du ministre de la Culture, des membres éminents du Musée national de Nouvelle-Zélande Te Papa Tongarewa et de Madame l'Ambassadeur de la NouvelleZélande en France... (voir article de Natacha Gagné ci-dessus). 